\title{
Changes of Variability in Response to Increasing Greenhouse Gases. Part II: Hydrology
}

\author{
RICHARD T. WETHERALD \\ NOAA/Geophysical Fluid Dynamics Laboratory, Princeton, New Jersey
}

(Manuscript received 10 September 2008, in final form 4 June 2009)

\begin{abstract}
This paper examines hydrological variability and its changes in two different versions of a coupled oceanatmosphere general circulation model developed at the National Oceanic and Atmospheric Administration/ Geophysical Fluid Dynamics Laboratory and forced with estimates of future increases of greenhouse gas and aerosol concentrations. This paper is the second part, documenting potential changes in variability as greenhouse gases increase. The variance changes are examined using an ensemble of 8 transient integrations for an older model version and 10 transient integrations for a newer model. Monthly and annual data are used to compute the mean and variance changes. Emphasis is placed on computing and analyzing the variance changes for the middle of the twenty-first century and compared with those found in the respective control integrations.

The hydrologic cycle intensifies because of the increase of greenhouse gases. In general, precipitation variance increases in most places. This is the case virtually everywhere the mean precipitation rate increases and many places where the precipitation decreases. The precipitation rate variance decreases in the subtropics, where the mean precipitation rate also decreases. The increased precipitation rate and variance, in middle to higher latitudes during late fall, winter, and early spring leads to increased runoff and its variance during that period.

On the other hand, the variance changes of soil moisture are more complicated, because soil moisture has both a lower and upper bound that tends to reduce its fluctuations. This is particularly true in middle to higher latitudes during winter and spring, when the soil moisture is close to its saturation value at many locations. Therefore, changes in its variance are limited. Soil moisture variance change is positive during the summer, when the mean soil moisture decreases and is close to the middle of its allowable range. In middle to high northern latitudes, an increase in runoff and its variance during late winter and spring plus the decrease in soil moisture and its variance during summer lend support to the hypothesis stated in other publications that a warmer climate can cause an increasing frequency of both excessive discharge and drier events, depending on season and latitude.
\end{abstract}

\section{Introduction}

In Stouffer and Wetherald (2007, hereafter Part I), the atmospheric temperature changes in both mean state and variability are examined for ensembles derived from two different versions of a coupled ocean-atmosphere model, an older model and a newer model, both developed at the National Oceanic and Atmospheric Administration (NOAA)/Geophysical Fluid Dynamics Laboratory. This current study continues the analysis of the integrations described in Part I, examining the changes of time mean state and variability of a number of hy-

Corresponding author address: Richard T. Wetherald, NOAA/ GFDL, Princeton, NJ 08542.

E-mail: dick.wetherald@noaa.gov drologic variables. Any change in the occurrence of floods and droughts is a topic of agricultural and societal importance. In a general way, this study attempts to estimate the future likelihood of changes in these events as greenhouse gas concentrations increase in the atmosphere.

It has been noted many times that changes in precipitation and many other hydrological variables have smaller signal-to-noise ratios than surface air temperature (SAT) changes (e.g., Houghton et al. 2001, chapter 9). Therefore, it is likely that the statistical significance of many of the hydrological variance changes presented here will be low. Furthermore, it was noted by Raisanen (2002) and Hunt and Elliot (2004) that changes in precipitation variability, in response to greenhouse warming, were generally much smaller than the corresponding 
time mean changes. Mearns (1993) evaluated diurnal and daily changes of precipitation variance in middle latitudes over the Central Great Plains of the continental United States and found that it increased during summertime.

However, as in Part I, a broader view is taken in this investigation. Changes are examined in the annual and seasonal hydrologic variability over the entire global domain. Emphasis is placed on those changes that seem related to large-scale changes of the mean state. Implicit in this study is the belief, as shown in Part I, that there are large-scale changes in the variance fields that may be closely related to changes in the mean state of the climate system.

It should be mentioned that most studies dealing with extreme events generally use daily data. However, because no daily data were saved from the R30 model, this was not a viable option for this investigation. Also, because this study takes a broader view of this subject, monthly mean and annual mean (AM) hydrologic data were considered to be adequate to identify the longterm changes in variability in response to the imposed radiative forcings.

As in Part I, the statistical method of Vinnikov and Robock (2002, hereafter VR) is used to compute the variance time series and the detrending of those variances. This method separates the changes of mean climate from the changes of variance without altering the variance time series themselves. See the appendix for a complete description of the method.

The purpose of this study is fourfold. Although there is a multitude of studies documenting the increase of precipitation variance with its mean with regard to natural climate variations and comparing these results with model simulations [see references on the Program for Climate Model Diagnosis and Comparison (PCMDI) Web site, which are available online at http://www-pcmdi. llnl.gov/ipcc/subproject_publications.php], relatively few of these studies investigate this relationship with regard to anthropogenic greenhouse warming (e.g., Benestad 2006; Kharin et al. 2007). Second, an attempt is made to establish a link between changes of variability of precipitation, runoff, and soil moisture, something which has not been studied extensively to date. Third, this study attempts to further substantiate statements made in previous and the 2007 Fourth Assessment Report (AR4) of the Intergovernmental Panel on Climate Change (IPCC) that greenhouse warming has the potential of increasing the frequency and intensity of both floods and droughts. Finally, it evaluates the performance of two completely different climate models developed at the Geophysical Fluid Dynamics Laboratory with regard to hydrologic changes.

\section{Model description and integration procedure}

As in Part I, the two models used in this investigation are 1) an older generation model, which will be referred to as the R30 (Manabe Climate Model; Delworth et al. 2002), and 2) a newer model version called CM2.1 (Delworth et al. 2006). Here, simply the main features of both models are highlighted [for more details, see Part I, Delworth et al. $(2002,2006)$, and references therein].

Because this paper deals entirely with hydrologic changes, it is worthwhile to describe in more detail both the precipitation and land surface schemes used in both models. In the R30 model, surface hydrology and precipitation are computed using a geographically uniform $15-\mathrm{cm}$ "bucket" and the "moist convective adjustment" scheme, respectively, which are described by Manabe (1969). Runoff is computed when the amount of liquid water exceeds the field capacity of the bucket. Evaporation is prorated according to the ratio of actual soil moisture to its field capacity. Cloud cover is a function of relative humidity only. No heat storage is allowed in the land surface.

The CM2.1 land surface component is described in Milly and Shmakin (2002) and is similar in complexity to the Manabe bucket scheme, especially for hydrological processes. However, an additional feature is the use of a global distribution of field capacities derived from vegetation and soil type datasets, which replaces the uniform $15-\mathrm{cm}$ field capacity used in the R30 model. Evaporation is prorated the same way as for the R30 model, except it includes a parameterized stomatal resistance and the field capacities are now variable. The CM2.1 land surface component allows heat storage over the continents.

In CM2.1, precipitation is computed according to the relaxed Arakawa-Schubert formulation of Moorthi and Suarez (1992). In general, large-scale clouds and cloud microphysics are determined according to Rotstayn (1997), whereas cloud amount is forecast based on the general scheme given by Tiedtke (1993). Here, aerosols do not interact with the cloud physics in any way.

The experimental procedures used to initialize and integrate both the R30 and CM2.1 models are described in Part I. For the R30 model, an ensemble of 8 transient integrations and corresponding control integrations are analyzed (Wetherald and Manabe 2002). For all eight of the transient integrations, the IS92a scenario of the Intergovernmental Panel on Climate Change (Houghton et al. 1992) was used.

For CM2.1, initialization and radiative forcing are quite different from those used for the R30 model. Again, the details of this procedure are given in Part I, including the method used by Stouffer et al. (2004) to 

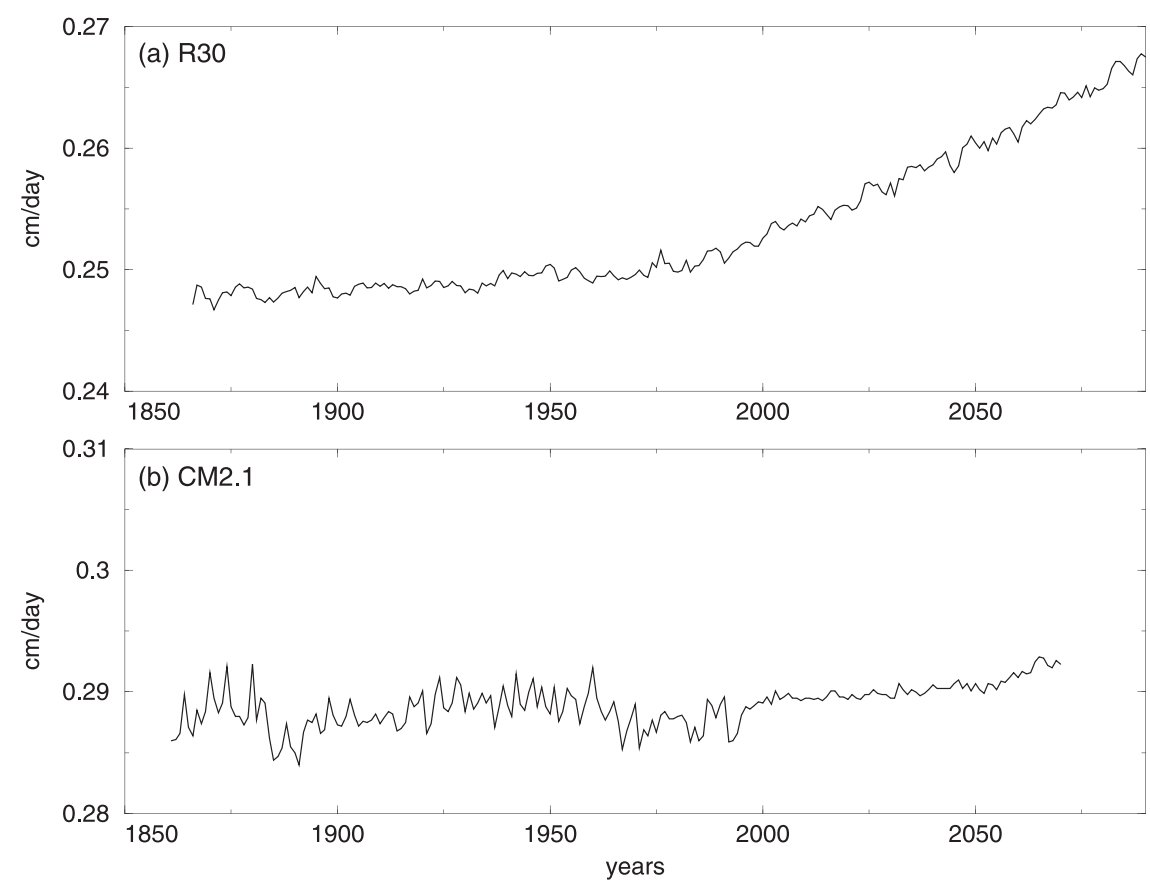

FIG. 1. Ensemble average of the time evolution of globally averaged precipitation (a) from 1860 to 2090 of the R30 IS92a scenario and (b) from 1860 to 2070 of the CM2.1 SRES A1B scenario. Units: $\mathrm{cm} \mathrm{day}^{-1}$. Note in (b) that, in the time period from year 1860 to 2000 for CM2.1, the same historical integration was used for each ensemble member, which explains the apparent increase in temporal variability in this time period.

obtain the control integration. For the CM2.1 model, the control integration climate drift is larger than in the R30 model. Therefore, a $100-\mathrm{yr}$ period was selected that corresponded in time with the analysis period (years 2035-2065) used for the transient experiments. However, this is only true for the annual or seasonal mean distributions of CM2.1, which are changing with time; for the detrended variance computations that are not changing with time, the entire 900-yr record is used.

A number of different future radiative forcing scenarios were run using CM2.1 in support of the IPCC AR4. An ensemble of 10 integrations using the Special Report on Emission Scenarios (SRES) A1B scenario (for a description, see Nakicenovic and Swart 2000) is analyzed in the same manner as the results from the R30 model. In this case, all 10 members started from year 1990 of the CM2.1 historical run described earlier, using small perturbations in the initial conditions to obtain the different ensemble members. It should be noted here that the radiative forcing in the IS92a scenario is somewhat larger than in the SRES A1B scenario. All other factors being equal, one would expect a larger climate response in the R30 results than is found in the CM2.1 results because of the larger radiative forcing.

The model data analyzed in this study consist of both yearly and monthly mean time series from the ensemble of 8 transient experiments from the R30 model and 10 transient experiments from the CM2.1 model plus their respective control runs. The analysis presented here focuses on a time period in the middle of this century (2035-2065). The response is presented as differences from preindustrial control integrations. The 2035-2065 calendar-year time period is chosen because it coincides with the time period analyzed in Wetherald and Manabe (2002). If a later time period had been chosen (e.g., year 2100), the amplitude of the changes would probably have been somewhat larger and possibly more statistically significant, but the patterns would have remained similar, assuming the sampling issues are small. Implicit in this statement is the assumption that the responses to the external forcings are approximately linear (see, e.g., Fig. 1 from year 2000 onward).

The variance ratio tests that were used for temperature in Part I cannot be directly applied to hydrological variables, such as precipitation, that are not normally distributed, because they are bounded at zero. To alleviate this problem, the square root transformation has been applied (Brooks and Carruthers 1953; Panofsky and Brier 1968). Various tests were conducted to insure that this transformation yielded nearly normally distributed data. However, this procedure has only been applied to the variance ratio computations; the annual, monthly, 
and seasonal means, as well as the trend analysis, are evaluated from the raw, untransformed data. Although it is true that the square root transformation is also bounded at zero, practically all of the analysis presented in this study takes place from middle to higher latitudes, where extreme dryness does not occur very often. Therefore, this should not be a major problem for the annual, seasonal, and monthly mean data analyzed here.

According to the VR method, a quadratic function [Eq. (A2)] is fitted separately at all grid points, and the spatial variances of deviations from that quadratic trend are then calculated for each point in time for each model ensemble member and averaged. Transient data for years 2035-2065 from each of the ensemble members are used, centered at year 2050. Variance ratios are defined as the variance of the transient experiments divided by their respective averaged control variances. This enables one to evaluate the degree of significance using the standard $F$ test directly. For this particular study, the degrees of freedom used for the $F$ test are 29 for both model control runs ( 30 segments of $30 \mathrm{yr}$ for a total of $900 \mathrm{yr}$ ); 7 (from an ensemble of 8 runs) and 9 (from an ensemble of 10 runs) for the transient R30 and CM2.1 runs, respectively. These are probably very conservative estimates for the degrees of freedom, given the relatively low correlation of successive data points in a typical hydrologic time series, but they are consistent with those used in Part I. In any event, the corresponding critical $F$ values for decreases and increases of variance ratio for a given variable (two-tailed test; i.e., $5 \%$ at either end) at the $10 \%$ significance level are 0.517 and 1.934 for the R30 model and 0.538 and 1.857 for CM2.1. In this and subsequent figures of this nature, ratios greater than 1 will denote increases of variance, and ratios less than 1 will indicate decreases.

\section{Analysis and results}

As the radiative forcing increases, the planet warms (Part I) and the global hydrological cycle intensifies. By way of an overview, the increase in the global hydrological cycle is demonstrated by showing the time evolution of globally averaged total precipitation for both models. Although the baseline values are different for the two curves, it is clearly seen that the globally averaged precipitation response of the R30 model (Fig. 1a) is considerably greater than that found in the CM2.1 model (Fig. 1b). This is due, in large part, to the fact that the radiative forcing and associated global surface temperature response of CM2.1 is smaller than that found in the R30 model (Part I). A second reason for a smaller response in CM2.1 is its larger and likely more realistic oceanic heat uptake in the transient integrations (Russell et al. 2006; Stouffer et al. 2006). In addition, differences in the aerosol forcing between the two models may also be partly responsible for the differences in the precipitation response between the two models.

The R30 model tends to have a relatively large globally averaged precipitation response relative to other atmosphere-ocean general circulation models (AOGCMs) used in the Third IPCC Working Group I assessment (see Fig. 9.6 of Houghton et al. 2001, chapter 9). It appears that $\mathrm{CM} 2.1$ precipitation response would be on the low side in the same comparison, although the radiative forcing scenario used in CM2.1 is different from what is used in Houghton et al. (2001, chapter 9), making any quantitative comparison difficult.

The common features in the geographical response of the annually averaged mean precipitation rate changes between the transient experiments and the corresponding controls of both models include an increase of precipitation rate along or near the equator, an increase of precipitation in higher latitudes almost everywhere, and a general decrease of precipitation in the subtropics (Figs. 2a,d). However, the decreases in the mean precipitation rate are much more extensive and cover a larger area in the CM2.1 simulation than in the R30 simulation. This difference is particularly notable in the Southern Hemisphere ( $\mathrm{SH}$ ) subtropics from South America to Africa and across the Indian Ocean and in the area surrounding the Mediterranean Sea.

As stated earlier, annually averaged precipitation rate differences in higher latitudes are mostly positive for both models, although these changes are smaller in magnitude for CM2.1. This is probably due, in part, to the SAT response being somewhat smaller in CM2.1 than in the R30 model (see Part I). The greater reduction of mean precipitation rate over the southern half of the United States and Europe in CM2.1 (Fig. 2d) would imply that these land areas generally experience drier conditions than in the R30 simulation. This will have an impact on the corresponding soil moisture changes, as discussed later. The drying in the Sahel region in CM2.1 is also notable (Held et al. 2005).

Figures $2 b$,e assess the signal-to-noise ratio distributions corresponding to the annual mean changes shown in Figs. 2a,d, respectively. In general, only the changes in higher-latitude regions in both hemispheres may be detectable (i.e., signal-to-noise ratio greater than 1) at this point in time. These results indicates that, even for annual mean changes, statistically significant or detectable changes in hydrologic quantities will, in all probability, require considerably longer integrations with greater radiative forcing than were performed here.

Because precipitation is zero bounded, an increase in the precipitation rate will generally result in an increase 
(a)

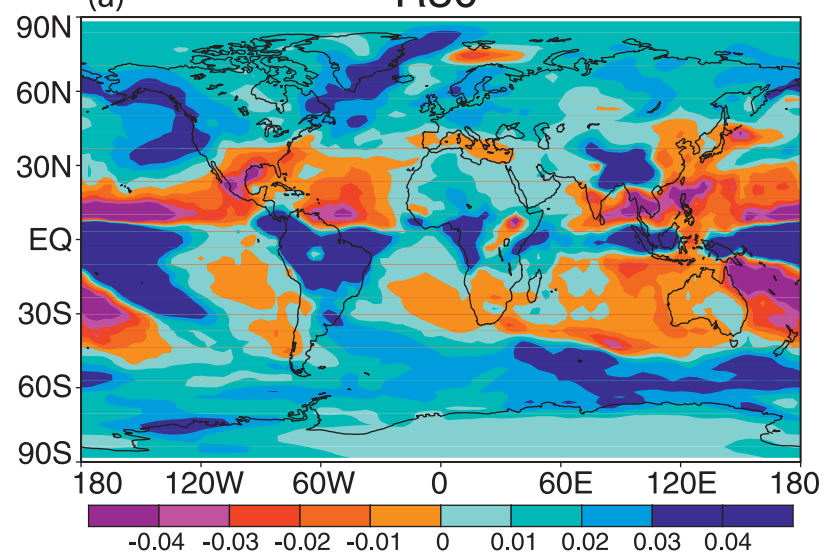

(b)

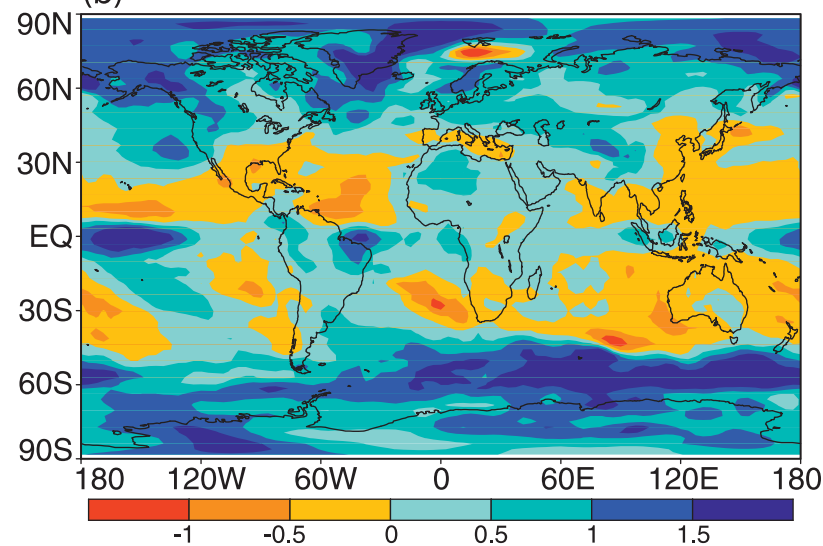

(c)

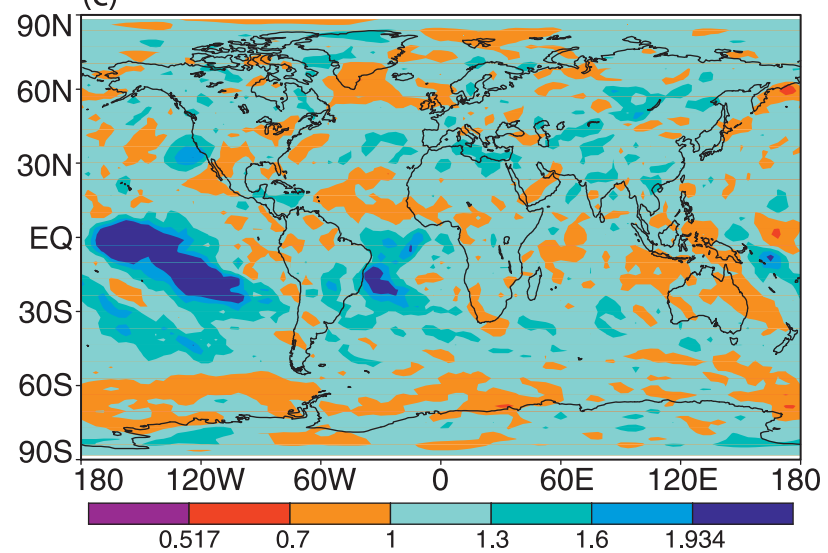

(d)

CM2.1

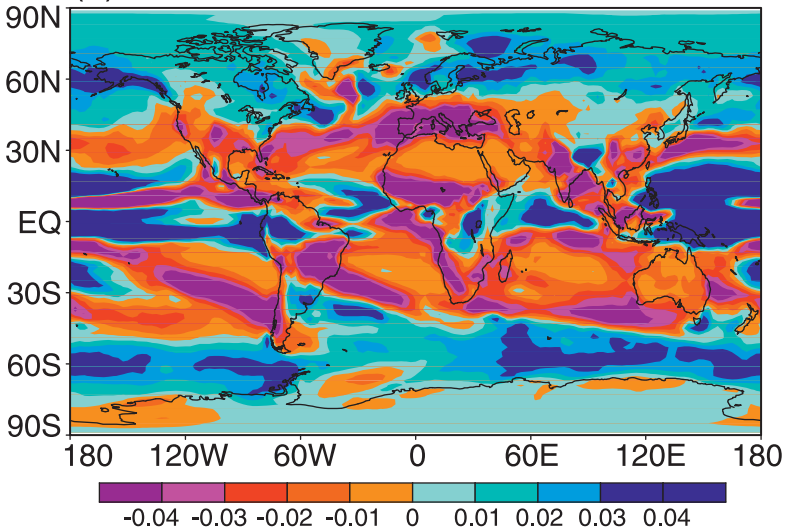

(e)

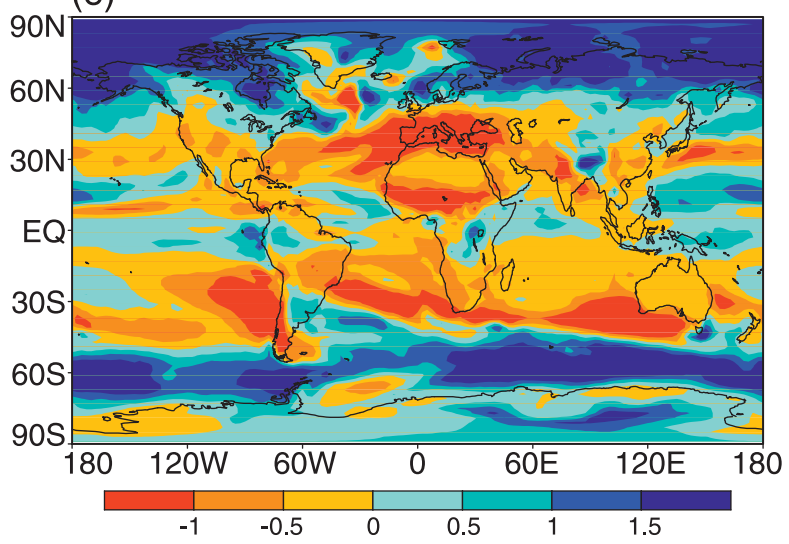

(f)

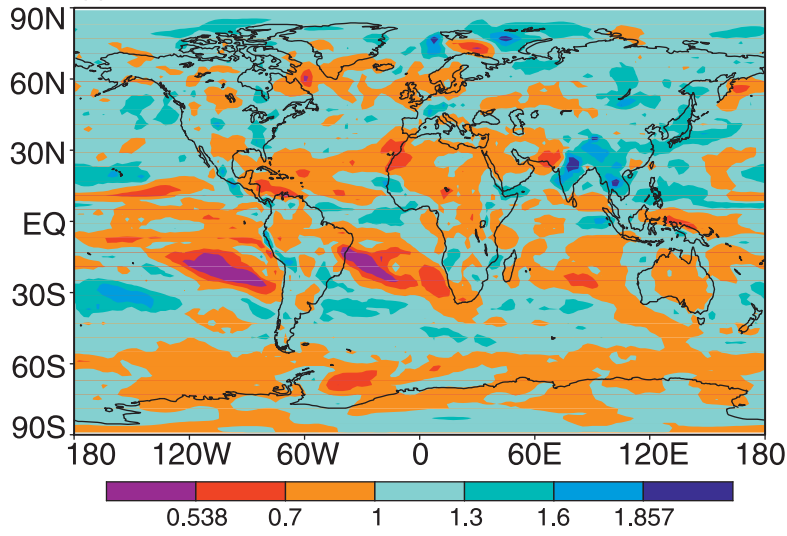

FIG. 2. Horizontal distribution of annually averaged (a) precipitation difference between the ensemble of integrations and the control from the R30 model; (b) signal-to-noise ratio of the AM differences shown in (a); and (c) variance ratio for the R30 model. (d)-(f) As in (a)-(c), but for CM2.1 model. Signal-to-noise ratios greater than one indicate regions where the signal begins to emerge from the noise. Variance ratios $<1$ denote decreases in variance, whereas ratios $>1$ denote increases. For variance ratios, regions of significance are denoted by dark blue for increases and dark red-purple for decreases. Units: $\mathrm{cm} \mathrm{day}^{-1}$ for (a),(d) and dimensionless for (b),(c),(e),(f). For this and all subsequent figures involving variance ratio computations, the square root transformation was applied to the raw data. See text for more details. 
of its variance. This is shown by examining the ratio of annual mean precipitation variance of the transient experiments to the variance of their respective controls for both models (Figs. 2b,e). Here, it is seen that, although there is a general increase of variance from middle to higher latitudes for both models, none of the precipitation variance changes is statistically significant at the $10 \%$ significance level. In the tropics, variance changes are also small, except for relatively large increases over the eastern half of the tropical and subtropical Pacific Ocean and a smaller one off the coast of Brazil for the R30 model and smaller oceanic regions of decrease in the southern subtropics in CM2.1. Elsewhere, most of the ratio changes are relatively small.

Also, an analysis of the changes of mean precipitation variance shown earlier indicates that the generally positive changes in variance ratio in middle to higher latitudes are relatively small in comparison to the mean changes. A similar result was obtained by Raisanen (2002) and Hunt and Elliot (2004), who noted that, although there were changes in interannual monthly mean precipitation variability in response to greenhouse warming, these were found to be relatively small in comparison to the time mean changes.

A statistic that is frequently shown in hydrologic studies is the average number of dry days per year (a dry day is defined here as days where precipitation is less than $1 \mathrm{~mm}$ day $^{-1}$ ). Figure 3 a shows an excessive number of dry days occurring in the expected regions, such as the polar and subtropical latitudes for the CM2.1 model. A comparison of the difference in the number of dry days per year (Fig. 3b) and the annual mean difference of precipitation (Fig. 2d) indicates an increase of dry days in regions where precipitation itself reduces (i.e., the United States, southern Europe, central South America, and Australia) and a decrease of dry days from middle to higher latitudes, where precipitation generally increases. Therefore, this statistic is consistent with the geographical changes of annual mean precipitation (cf. Fig. 2d). These results, as well as those shown in Fig. 2d, are consistent with those obtained by Sun et al. (2007), which indicated that, for the latest generation of coupled climate models submitted to the 2007 Fourth Assessment Report of the IPCC, drier subtropical regions experience decreased precipitation intensity and frequency, whereas higherlatitude and midlatitude regions, which are generally wetter, will experience increased precipitation intensity and frequency. In other words, there is a tendency for wet regions to get wetter and dry regions to get drier under greenhouse warming scenarios. This latter conclusion was also reached previously by Manabe et al. (2004).

Because the annually averaged precipitation rate generally increases in higher latitudes in both models as well (a)

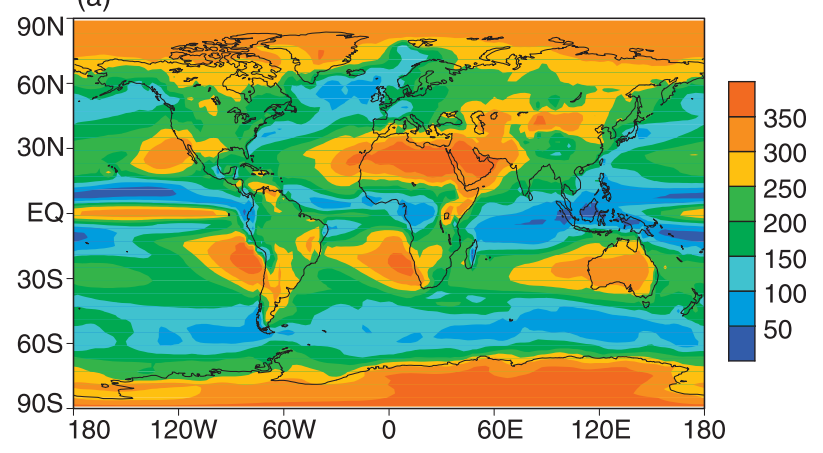

(b)

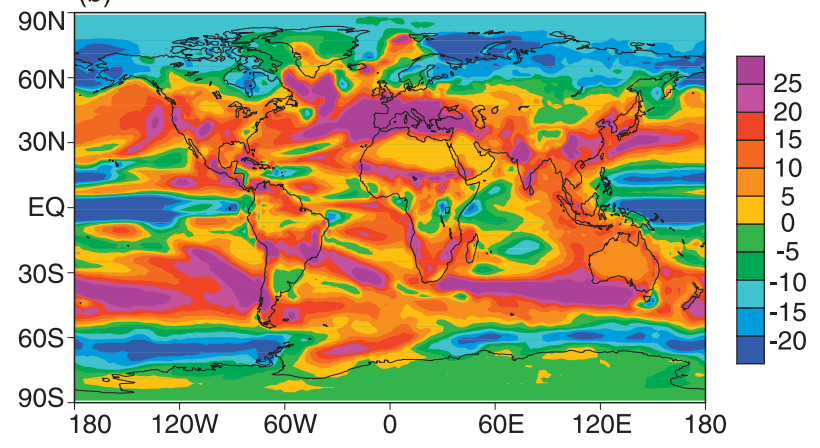

FIG. 3. AM (a) average number of dry days per year from the control run of CM2.1 and (b) difference between the ensemble of integrations and the control of the average number of dry days per year from CM2.1. Dry days are defined as days where the precipitation rate is $<1 \mathrm{~mm}^{\text {day }}{ }^{-1}$. The averaging periods are as in Fig. 2.

as in many other previous studies because of greenhouse warming, the robustness of the corresponding changes of variance is shown. Here, the VR method is used to compute the trend of the variance time series for each member of both the R30 (Fig. 4a) and CM2.1 (Fig. 4b) ensembles for the latitudinal zone of $60^{\circ}-90^{\circ} \mathrm{N}$. Variances are computed by the same method as described previously, but they are further processed by fitting them to linear trends [Eq. (A3)]. Here, the square root transformation has been applied to the data prior to computing these slopes.

All ensemble members of the R30 and CM2.1 models (Fig. 4) exhibit a positive slope of precipitation variance change. This indicates that the variance of annually averaged precipitation rate is generally increasing in high northern latitudes. The main difference between the two model precipitation variance trends is that those in the CM2.1 model are considerably smaller than those found in the R30 model. The statistical significance of these slopes will be discussed later.

The monthly, zonally averaged changes in mean local precipitation rate over land regions only are shown in Figs. 5a,b for both the R30 and CM2.1 models. The following general features are evident: relatively large 

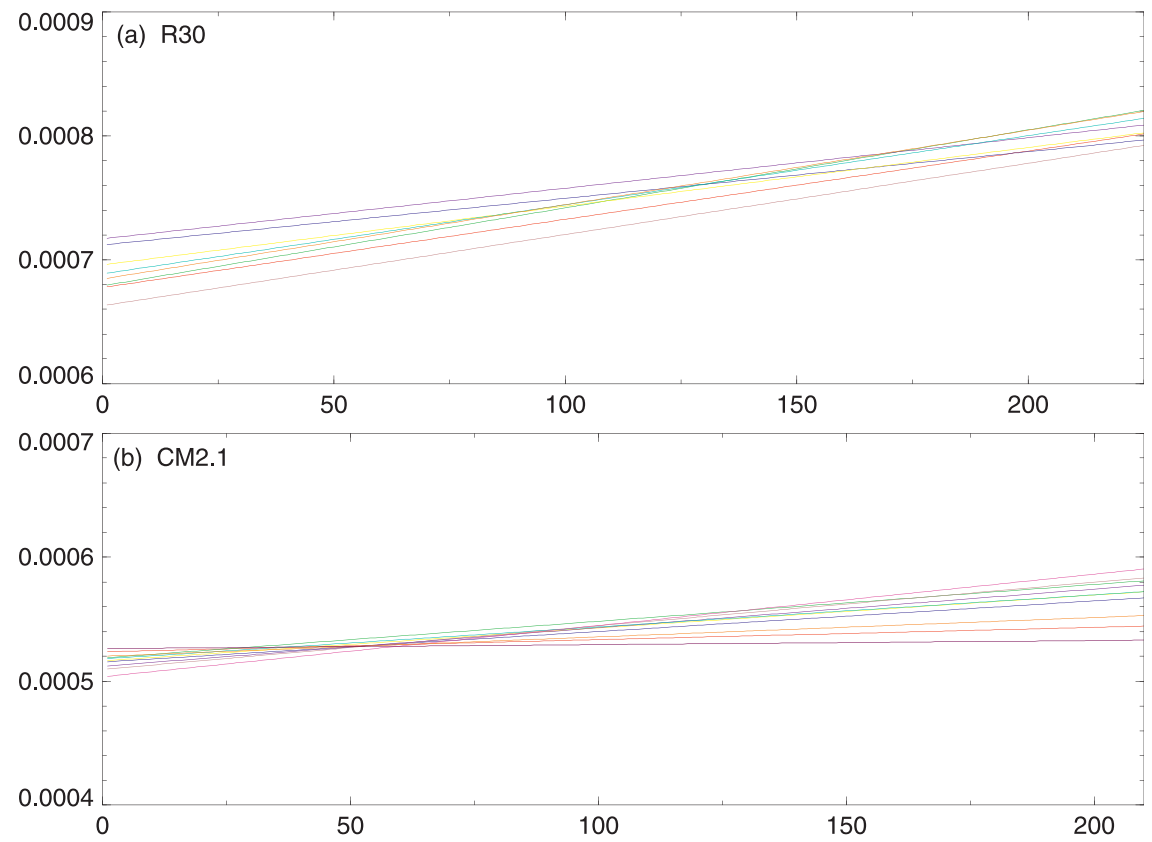

FIG. 4. Variance time series trend of precipitation rate for each transient integration, as computed by linear least squares and integrated over the zonal belt of $60^{\circ}-90^{\circ} \mathrm{N}$ for both land and sea. Results are shown for (a) the R30 model taken over 225 model years and (b) the CM2.1 model taken over 210 model years. The slope of each line is given by the coefficient $b_{2}$ [see Eq. (A3) in Part I] for each case. Units are $\mathrm{cm} \mathrm{day}^{-1}$ for both R30 and CM2.1. The square root transformation has been applied to the data prior to computing these slopes.

mean precipitation rate increases occur for most seasons in both the ITCZ region and higher northern latitudes for the two models. This is particularly true for the R30 model. However, more moderate precipitation rate increases also occur in many other regions for the R30 model, whereas the CM2.1 mean precipitation rate decreases in middle northern latitudes in June-August (JJA) and throughout the year from $30^{\circ}$ to $40^{\circ} \mathrm{N}$. It also decreases in the subtropics and tropics other than the ITCZ during most months in CM2.1. The implications of this decrease of mean precipitation rate in middle latitudes from late spring through early fall in CM2.1 for other variables will be discussed later.

The corresponding variance ratios for the two models reveal that both distributions are well below the $10 \%$ significance level (Figs. 5b,d). There is a tendency for an increase in variance at higher latitudes for both models but very little correspondence elsewhere.

The Northern Hemispheric (NH) zonally averaged mean precipitation rate differences are negative in middle latitudes during late spring, summer, and early fall for CM2.1 (Fig. 5b). This is illustrated in more detail in Fig. 6, which indicates relatively large negative mean precipitation rate differences over both North America and southern Europe for CM2.1 during JJA (Fig. 6d). For the R30 model (Fig. 6b), most of the differences in the same areas are weakly positive. This highlights the uncertainty of the regional precipitation response in climate models (Houghton et al. 2001, chapter 9; Meehl et al. 2007).

For the December-February (DJF) season, there are general increases of mean precipitation rate over mid- to high-latitude land areas for CM2.1 (Fig. 6c) and the R30 model (Fig. 6a). In both models, there is a tendency for the Mediterranean region to experience less precipitation during the DJF season, although this tendency is much more extreme for CM2.1. The reductions in mean precipitation rate in the tropics and subtropics are also much greater and more extensive in CM2.1 than in the R30 model. Australia also experiences less precipitation during its winter season (JJA) in both models.

At this point, it is worthwhile to compare the multimodel average DJF and JJA mean precipitation differences presented in Fig. SPM.7 of Alley et al. (2007) to the distributions in Fig. 6. This comparison reveals that the positive and negative patterns from the CM2.1 model resemble more closely those of Fig. SPM.7 of Alley et al. (2007) than the ones from the R30 model. This may be attributable to the CM2.1 model incorporating the additional features not contained in the R30 model.

The monthly zonally averaged differences of mean land runoff between transient and control integrations for both models (Figs. 7a,c) follows the pattern noted in 
(a)

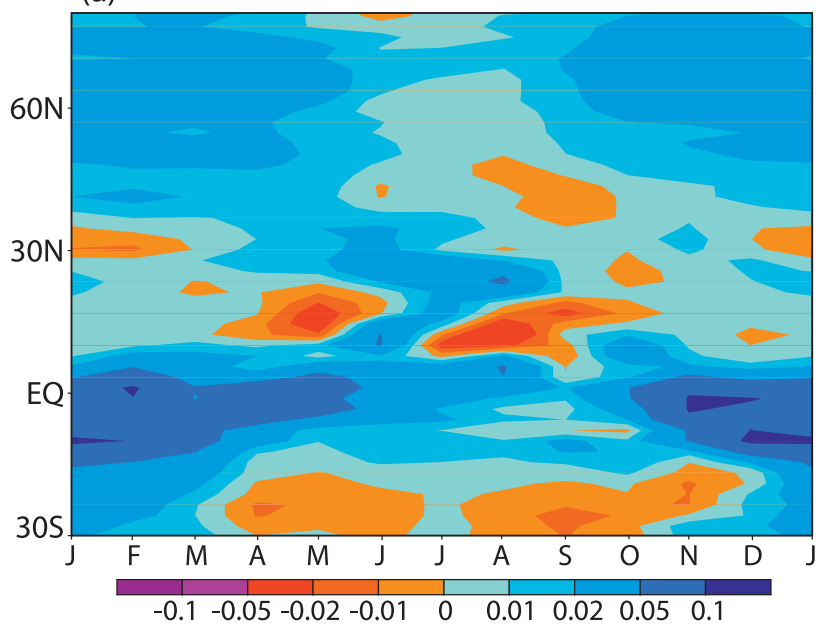

(b)

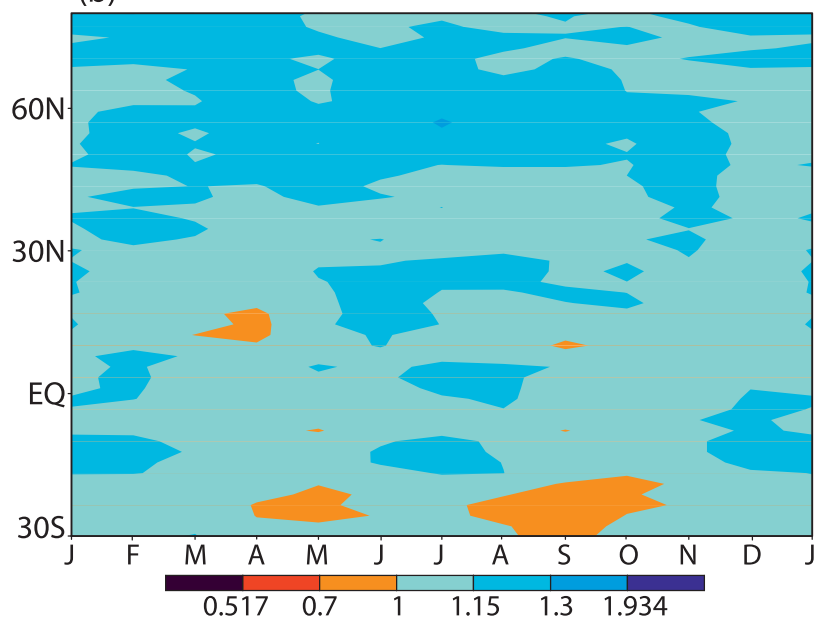

(c)

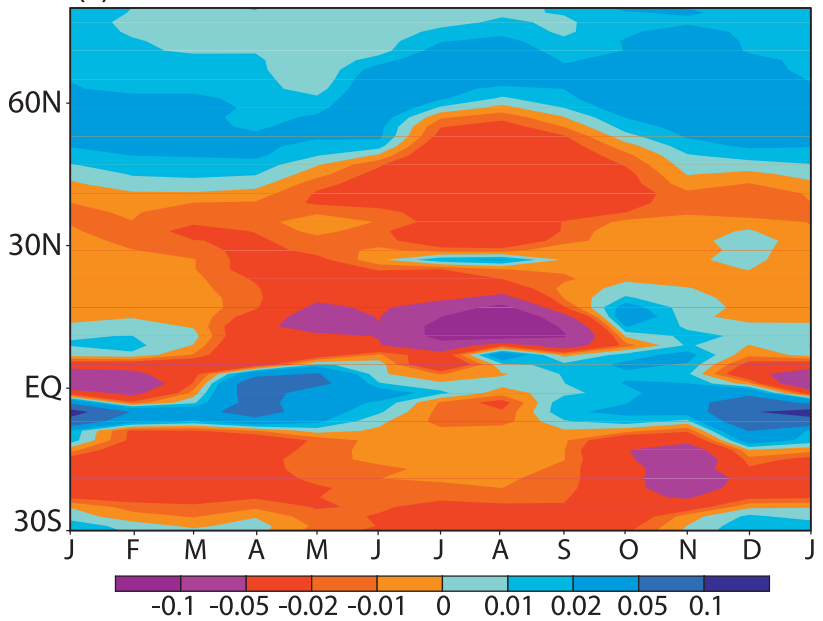

(d)

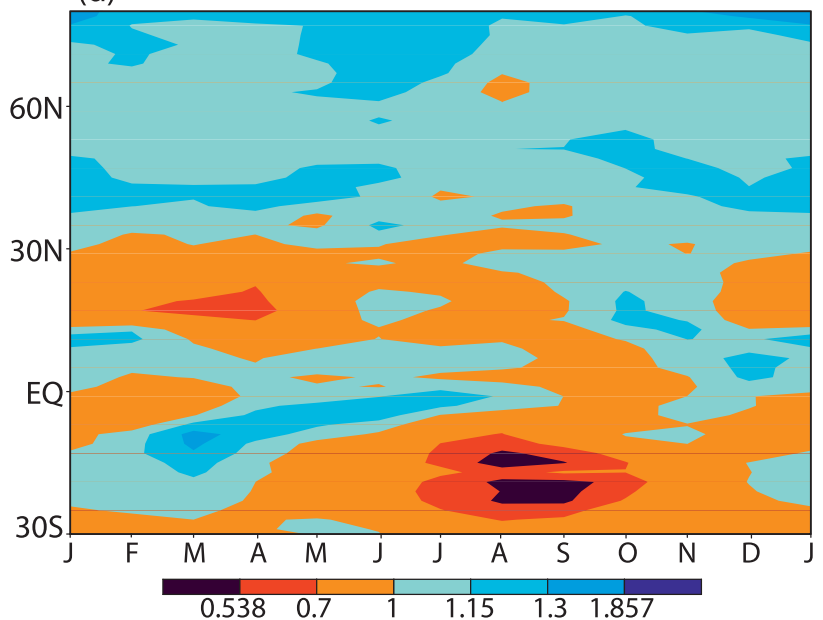

FIG. 5. Latitude-time distribution over land of zonally averaged (a) difference between the controls and ensemble of integrations of precipitation rate and (b) transformed variance ratio for the R30 model; (c),(d) As in (a),(b), but for the CM2.1 model. The averaging time periods are the same as in Fig. 2. Here, the zonal average is computed from the local mean and variance values. Units: $\mathrm{cm}^{\mathrm{day}}{ }^{-1}$.

previous studies of greenhouse-induced hydrologic change (Manabe and Wetherald 1987; Houghton et al. 2001, chapter 9; Meehl et al. 2007). In the Northern Hemisphere $45^{\circ}-70^{\circ} \mathrm{N}$ region, there is a maximum of runoff increase in either late winter or early spring, depending on latitude, followed by a period of runoff decrease a month or two later. This pattern of change is due to an earlier occurrence of the spring maximum of both rainfall and particularly snowmelt in northern middle to higher latitudes. There are also increases in runoff associated with the increases of precipitation in the tropical rain belt for most of the year, although these are narrower and smaller in magnitude in CM2.1 than in the R30 results. The patterns of mean runoff change for both R30 and CM2.1 are similar but with greater reductions in runoff in CM2.1, particularly during the summer season in $\mathrm{NH}$ middle latitudes.
The changes in land runoff variance (Figs. 7b,d) may be summarized as follows: for both models, runoff variance increases in the tropics and subtropics for much of the year, although there are some instances of decreases as well, especially for CM2.1. Runoff variance also increases in $\mathrm{NH}$ middle to higher latitudes during fall, winter, and early spring. The increase of runoff variance is then followed in time by a corresponding decrease in runoff variance during late spring and early summer.

As is the case for precipitation, runoff variance tends to increase in the same regions and months as the increases in the mean runoff (cf. Figs. 7a,b; cf. Figs. 7c,d). The general conclusion here is that, as the mean runoff increases, the runoff variance also increases. In large measure, this is consistent with a greater likelihood of more extreme river discharge events or frequency of " 100 year" floods noted in the study of Milly et al. (2002) and 
$\mathrm{R} 30$

(a) DJF

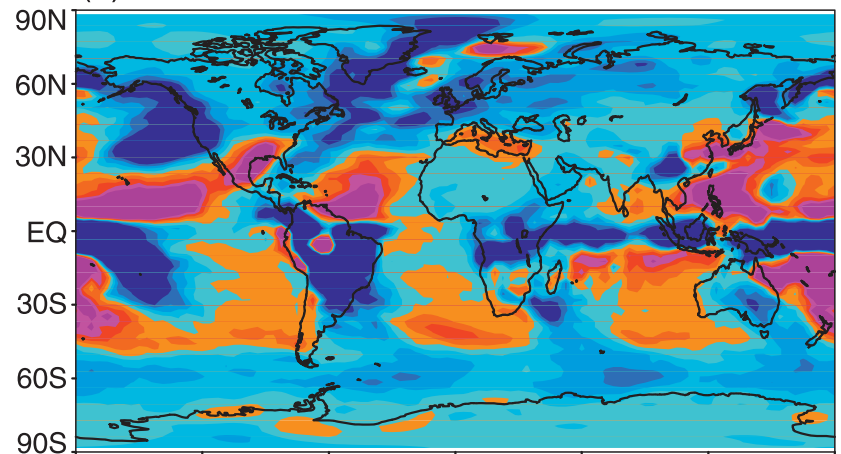

(b) JJA

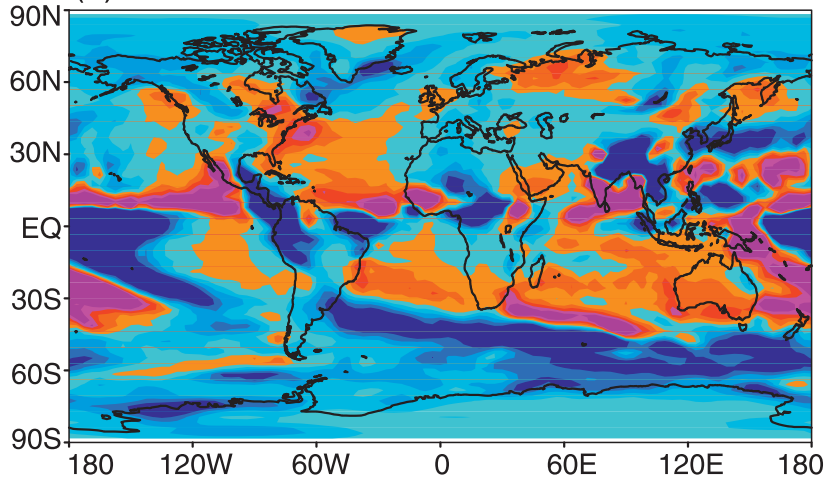

(c) DJF

CM2.1

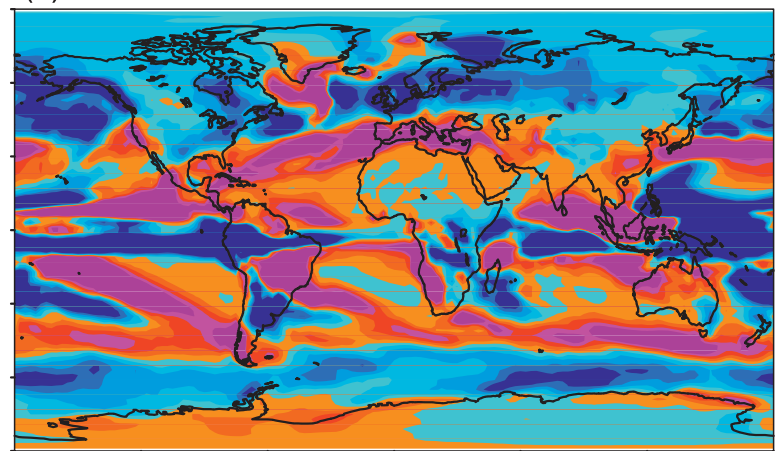

(d) JJA

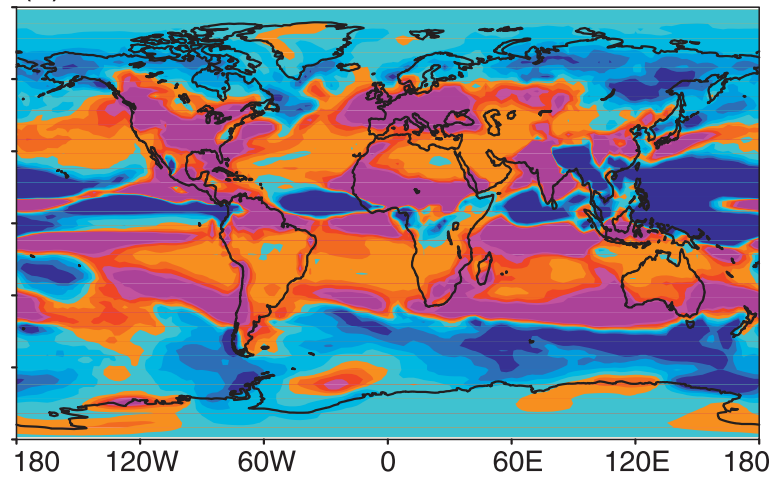

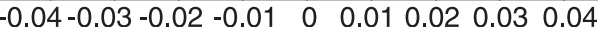

FIG. 6. Horizontal distribution of mean precipitation rate difference for both DJF and JJA seasons. Results are shown for the R30 model (a) DJF and (b) JJA and for CM2.1 (c) DJF and (d) JJA. The averaging time periods are as in Fig. 2. Units: $\mathrm{cm}^{\text {day }}{ }^{-1}$.

runoff increases illustrated in Wetherald and Manabe (2002) and Manabe et al. (2004) in response to increasing greenhouse gases. This conclusion is also consistent with Milly et al. (2005) and Nohara et al. (2006), who projected an increase of extreme events in a global warming world by analyzing the results of 12 and 19 different climate models, respectively, that were submitted to the 2007 Fourth Assessment Report of the IPCC. Therefore, given that the mean runoff changes described earlier are very robust because of the strong relationship with the greenhouse warming, it is speculated that the changes in the runoff variance discussed earlier that are related to those mean runoff changes are also robust.

In lower latitudes, the only correspondence between increased runoff and its variance occurs in CM2.1 in near $30^{\circ} \mathrm{N}$ during the latter half of the year. Otherwise, there is little change in variance in the tropics and subtropics.

The variance ratio $F$ test for the R30 model (Fig. 7b) reveals that the R30 fall-spring higher-latitude runoff variance increase is statistically significant at the $10 \%$ significance level. The comparable CM2.1 distribution of runoff variance increase is not significant in higher latitudes (Fig. 7d), although it comes quite close to this limit. However, the pattern of values is very similar to those found in the R30 model (light blue regions of Figs. $7 \mathrm{~b}, \mathrm{~d})$. The lack of statistical significance in CM2.1 is probably due to the smaller runoff variance response for CM2.1 as compared with the R30 model, a feature discussed earlier.

Land areas in middle to higher latitudes of the Northern Hemisphere appear to experience wetter winters and drier summers in both models (Figs. 8a,b) in terms of the soil moisture response. However, the drying out of the soil is much more pronounced and extensive in middle latitudes for the CM2.1 than for the R30 version. This tendency for greater drying during summer in CM2.1 is noted in Findell and Delworth (2005). However, many of the buckets in the control integration for the R30 model are considerably drier than those of the CM2.1 model in middle latitudes during the summer season, which limits further soil moisture reduction there. In any event, the mechanisms responsible for the summertime drying generally include an earlier snowmelt season, 
(a)

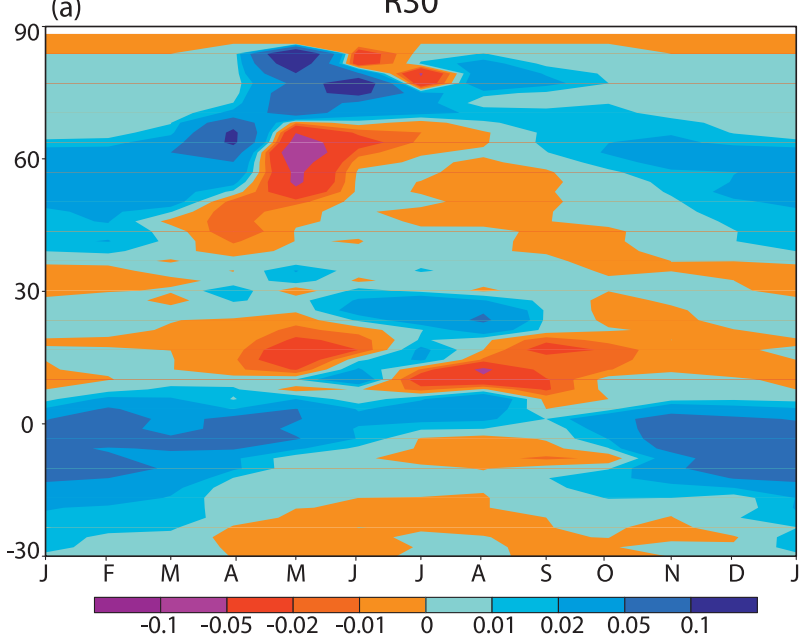

(b)

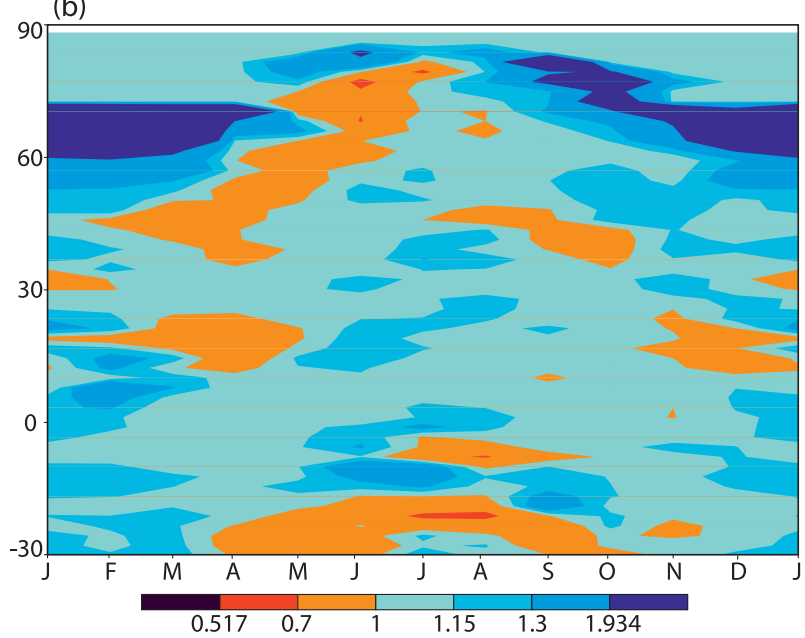

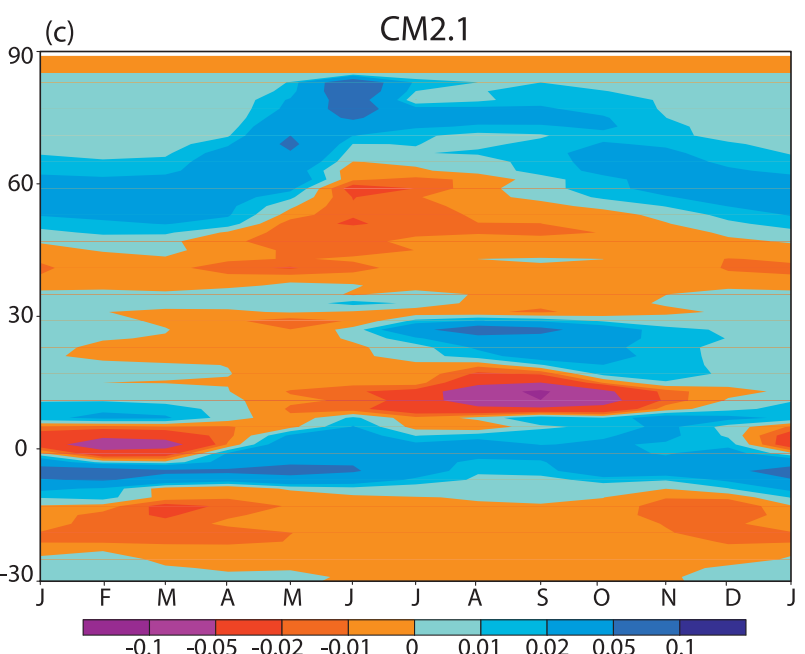

(d)

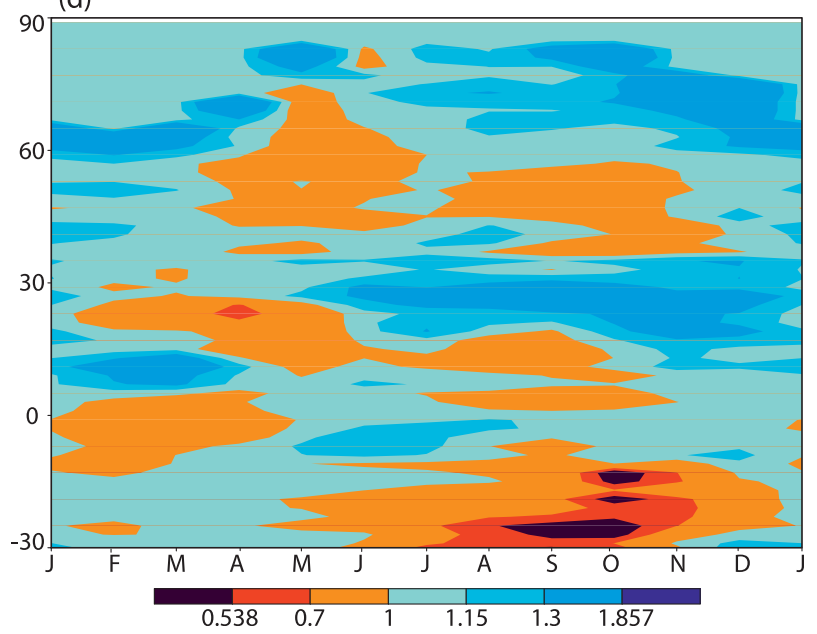

FIG. 7. Latitude-time distribution of zonally averaged (a) difference between the ensemble of integrations and the control of runoff rate and (b) and transformed variance ratio for the R30 model; (c),(d) As in (a),(b), but for the CM2.1 model. The averaging time periods are as in Fig. 2. Here, the zonal average is computed from the local mean and variance values. Units: $\mathrm{cm} \mathrm{day}^{-1}$.

increased evaporation, and a general reduction of lowlevel relative humidity (Manabe et al. 1981; Manabe and Wetherald 1987; Wetherald and Manabe 1995; Houghton et al. 2001, chapter 9; Meehl et al. 2007). This tendency for increased summertime dryness for many regions in northern middle latitudes was also obtained by Wang (2005), who analyzed 15 different models submitted to the IPCC Fourth Assessment Report. However, in CM2.1, the large decreases of summertime precipitation over North America and Europe also play a major role in the continental summer drying (Fig. 8b).

Because soil moisture in the two models is bounded both at 0 and their respective field capacities, the standard $F$ test is not really applicable in this case. However, tendencies can still be illustrated by showing the changes of soil moisture variance ratio itself, as in Figs. 8b,d. Although no estimate of statistical significance can be made on the basis of the $F$ test, Figs. 8 b,d nevertheless indicate that the variance difference of zonal monthly mean soil moisture increases during the summer months in middle to higher latitudes for both models.

Both distributions also indicate a reduction of soil moisture variance during the fall, winter, and early spring seasons, which is due to the soil moisture values in both models being near to their respective field capacities, and therefore its variance cannot increase much further. This is not the case during the summer season, when the soil moisture values are more in the middle of their allowable range and are freer to change without restriction.

Another method for analyzing soil moisture variance changes is to construct frequency plots of the local soil moisture values from both the R30 and CM2.1 models to demonstrate the overall changes in soil moisture variability in the zonal belt of $45^{\circ}$ to $60^{\circ} \mathrm{N}$. Because the soil 
(a)

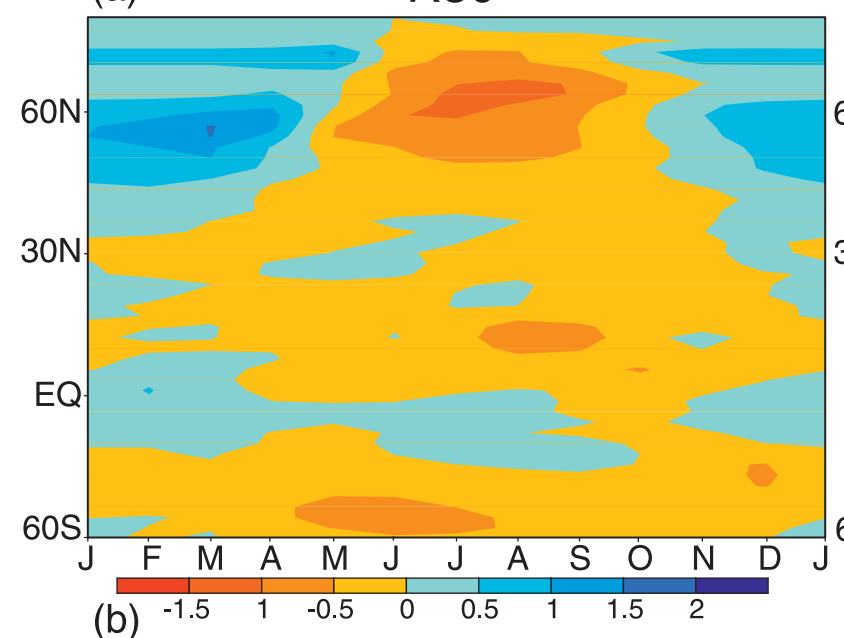

(c)

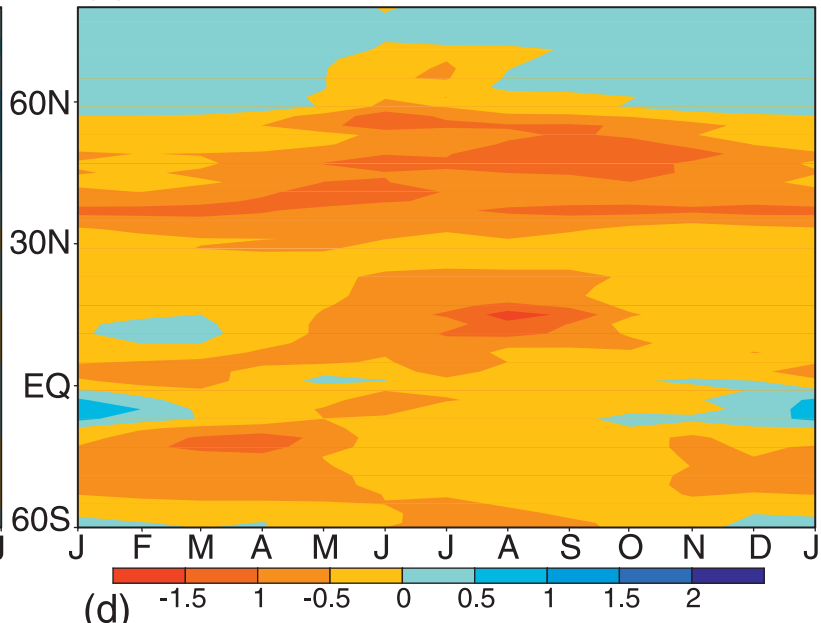

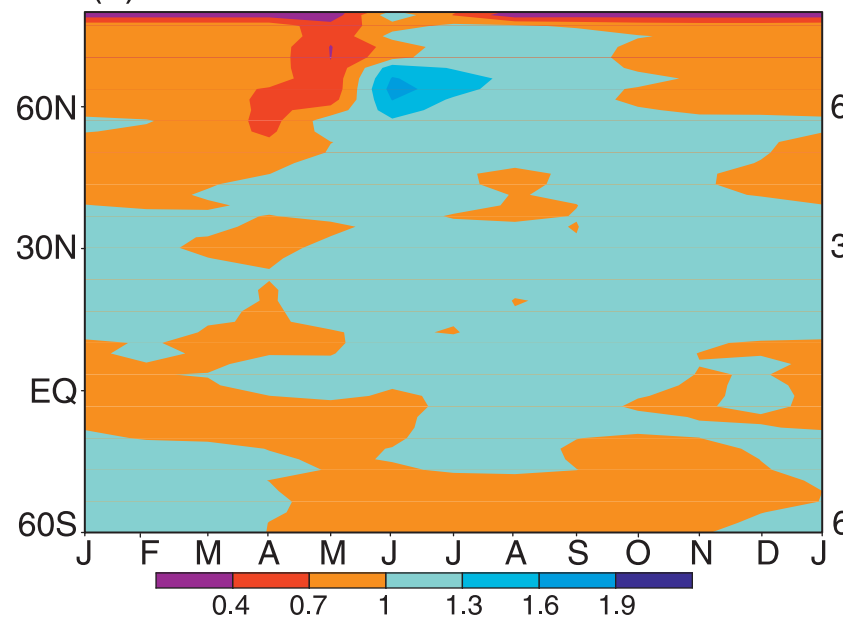

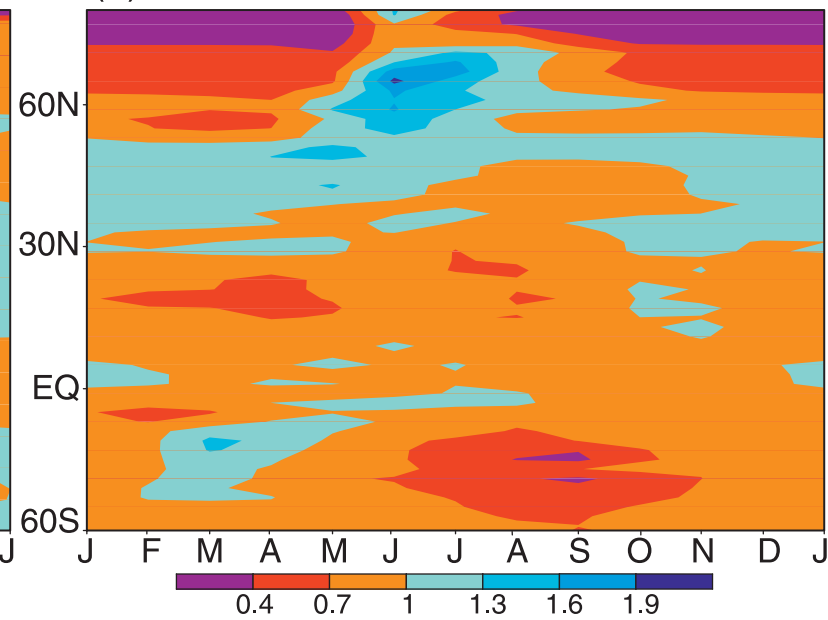

FIG. 8. Latitude-time distribution of zonally averaged (a) difference between the controls and ensemble of integrations of soil moisture and (b) transformed variance ratio for the R30 model. (c),(d) As in (a),(b), but for the CM2.1 model. The averaging time periods are as in Fig. 2. Here, the zonal average is computed from the local mean and variance values. Units: $\mathrm{cm} \mathrm{day}^{-1}$.

moisture values are very close to the maximum field capacity in DJF, only the JJA results are shown. Any change in the distribution during DJF is strongly influenced by its upper bound.

In both models, there is a tendency for the frequency distribution of the raw soil moisture data to shift toward smaller values as greenhouse gases increase (Figs. 9a,d). This shows that the soil moisture is generally decreasing in the zonal region of $45^{\circ}-60^{\circ} \mathrm{N}$ during JJA, as discussed earlier. An examination of the normalized frequency plots in Figs. 9b,c,e,f reveals a difference in the soil moisture response of the two models. In the R30 results, there is a clear shift toward a drier climate in the transient integration. The curves in Figs. 9b,c indicate that negative values increase over a much larger range, implying that the transient distribution is both shifting toward negative values and broadening. In CM2.1, the distribution simply broadens. Therefore, in both models, the changes in the normalized frequency distributions (Figs. 9b,c,e,f) indicate a reduction and broadening of the curves for the transient integrations, which suggests that the variance of soil moisture would increase during the summer months.

In summary, the analysis for precipitation and runoff presented previously along with the variance and frequency changes for soil moisture imply that, under greenhouse warming conditions, there is an increased probability of extreme precipitation events during late winter and early spring and an increased frequency and intensity of drier periods during summer in midlatitude Northern Hemisphere continental regions. Therefore, this investigation supports the hypothesis of an increased likelihood of these extreme events as stated in several IPCC reports (i.e., Houghton et al. 1990, 1996, 2001; 
R30
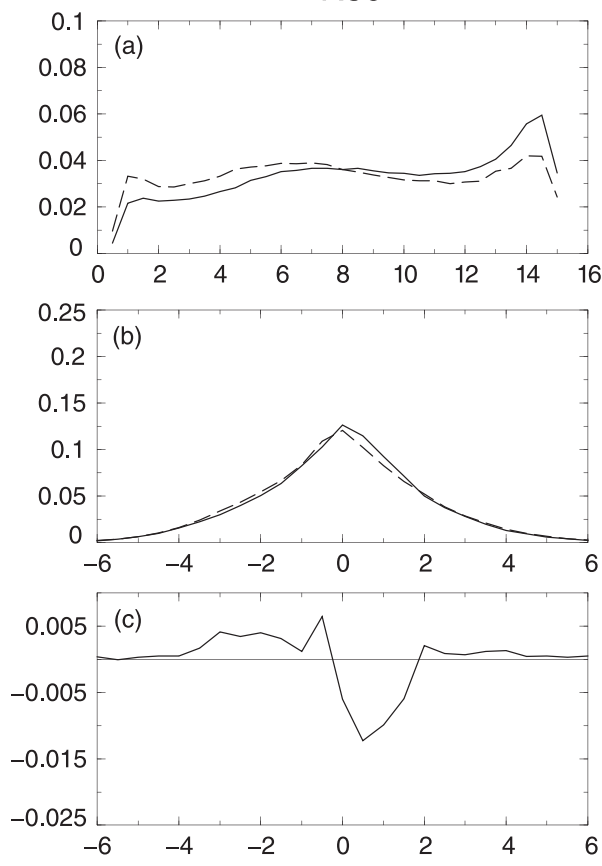

CM2.1
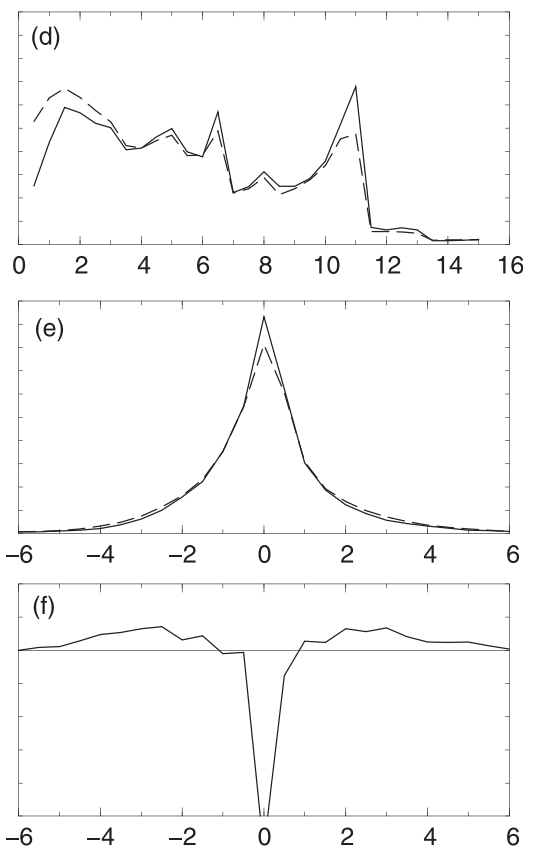

FIG. 9. Frequency distributions computed over the zonal belt of $45^{\circ}-60^{\circ} \mathrm{N}$ for occurrences of JJA soil moisture. (a)-(d) The solid lines represent data from the control integrations and the dashed lines represent data from the perturbation integrations. (a) R30 values; (d) CM2.1 values; (b) normalized R30 distributions; (e) normalized CM2.1 distributions; (c) normalized R30 difference between the transient and control integrations shown in (b); and (f) normalized CM2.1 difference between the transient and control shown in (c). The distributions were normalized by removing the local mean at each grid point in each integration to clearly show the shifts in the distributions. Units: $\mathrm{cm}$.

Meehl et al. 2007) in response to increasing greenhouse gases. In particular, Kharin et al. (2007) also indicated an increase in more extreme precipitation events based on daily data obtained from 16 coupled model experiments submitted to the IPCC archives, which corroborates the current investigation using monthly data.

Previously, it was shown that variance trends (slopes) of annual mean precipitation rates in higher northern latitudes were consistently positive throughout the entire periods of integration for both models (Fig. 4). Here, this issue is extended to include seasonal changes of both land precipitation and runoff in northern middle latitudes. This analysis is illustrated by Table 1 , which lists, for each ensemble, the smallest slope, the largest slope, the average slope, its variance, and the number of cases where the ensemble of slopes proved to be significantly different from zero according to Student's $t$ test. Table 1 is divided up into three subsections for both models: annual mean precipitation at $60^{\circ}-90^{\circ} \mathrm{N}$, seasonal mean precipitation over land at $45^{\circ}-60^{\circ} \mathrm{N}$ for DJF and JJA, and runoff for the same latitude region and seasons. Again, the square root transformation has been applied to the data prior to computing these slopes.
An examination of Table 1 reveals that most of the long-term trends of variance for all three quantities are positive and significantly different from zero according to the standard Student's $t$ test for at least the 5\% significance level, with the exception of the JJA runoff for the CM2.1 model. These results strongly support the conclusions made previously regarding increases of both precipitation and runoff variance in middle to higher latitudes during the winter and spring seasons. The same general observation may be made concerning the trend of variance of land precipitation during JJA, which implies that the variance of precipitation may be expected to increase during this season as well.

\section{Summary and conclusions}

As in previous studies, the hydrological cycle intensifies as greenhouse gases increase, and the climate warms for both of the models analyzed in this study. The mean values of the hydrological variables and their associated variance both change. For example, the mean precipitation rate tends to increase at most locations from middle to higher latitudes in response to increasing 
TABLE 1. List of minimum slopes, maximum slopes, mean slopes, mean slope variances, and number of cases where the various slopes in each group ( 8 for R30 and 10 for CM2.1) proved to be significantly different from zero according to the Student's $t$ test. Results are listed for each of the quantities and time periods given in the text: AM, DJF, and JJA. Units of the slopes are $\mathrm{cm}$ day ${ }^{-1} \mathrm{yr}^{-1}$ and have been scaled by a factor of $1.0 \times 10^{6}$ for ease of interpretation. The square root transformation has been applied to the data prior to computing these slopes.

\begin{tabular}{lcccc}
\hline & Slope $^{\text {min }}$ & Slope $^{\text {max }}$ & Slope $^{\text {mean }}$ & No. cases \\
\hline \multicolumn{2}{l}{ Precipitation $\left(60^{\circ}-90^{\circ} \mathrm{N}\right)$} & & & \\
R30: AM & 0.38 & 0.63 & 0.52 & 8 \\
CM2.1: AM & 0.03 & 0.41 & 0.33 & 7 \\
Precipitation: land $\left(45^{\circ}-60^{\circ} \mathrm{N}\right)$ & & & \\
R30: DJF & 0.26 & 1.80 & 1.06 & 6 \\
CM2.1: DJF & 1.10 & 2.36 & 1.60 & 6 \\
R30: JJA & 6.76 & 9.86 & 8.40 & 8 \\
CM2.1: JJA & 1.29 & 5.22 & 3.47 & 9 \\
Runoff (45-60 & & & \\
R30: DJF & 6.41 & 10.24 & 8.01 & 8 \\
CM2.1: DJF & 1.96 & 4.73 & 3.18 & 10 \\
R30: JJA & 6.62 & 10.88 & 8.13 & 8 \\
CM2.1: JJA & 0.01 & 1.17 & 0.62 & 0 \\
\hline
\end{tabular}

greenhouse gases. Because precipitation has a lower bound, increases in the mean precipitation rate generally lead to corresponding increases in its variance. However, it is found that the precipitation rate variance also increases in regions of small mean precipitation changes of either sign. Only in regions where there are relatively large mean precipitation rate decreases are there precipitation variance decreases.

The changes in precipitation variance then impact the other hydrological variables, such as runoff and soil moisture. In particular, an increase in the precipitation variance will usually lead to an increase in the runoff variance. In most locations, there are small general increases in the runoff variance. However, in high latitudes the spring snowmelt season occurs earlier in the year because of the warming of the planet. This shifts the mean runoff maximum and its variance to earlier in the year. Because this runoff variance shift is related to a robust physical mechanism, it is speculated that the variance changes also are robust. In particular, the variance increases of both land precipitation and runoff during the December-February season in northern middle latitudes are strongly supported by a statistically significant trend analysis performed on these quantities.

The changes in soil moisture variance are more complicated because soil moisture is constrained by both an upper and lower bound. Many land locations approach these bounds during the normal seasonal cycle of soil moisture in a given control integration. Despite this, it is found that the variability of soil moisture in middle latitudes in the Northern Hemisphere increases during summer, whereas the mean decreases. These results for soil moisture, taken together with the variance increases of precipitation and runoff during winter and spring, support the discussion in the IPCC reports that greenhouse warming has the potential of causing increased occurrences of extreme weather events in middle to higher latitudes.

In the tropics and subtropics, the mean and variance changes of the various hydrological variables are less consistent between the two models results. For example, the mean precipitation rate decreases in the subtropics are much larger in the CM2.1 results than in R30. However, for both models, large increases of annual mean precipitation generally correspond to increases of its variance. In particular, the mean and variance of precipitation and runoff rate increase for both models in the ITCZ, although this region of increase is considerably narrower in latitudinal extent in CM2.1 than in R30.

As noted at the end of Part I, the results presented here should be regarded as tentative at this stage. Had it been possible to perform this analysis on longer time integrations, it is very likely that the variance changes would have been larger and more statistically significant. Also, the use of a conservative estimate for the degrees of freedom limited the occurrence of statistically significant regions in this study.

Although there are several similarities of hydrologic response from one model to the other, it is noted that the differences of seasonal mean precipitation obtained from the CM2.1 model appear to more closely resemble the distributions derived from the ensemble of models presented in the Fourth Assessment Report of the IPCC. This is attributable to more recent improvements made to the CM2.1 model, which were not available for the earlier model.

One recommendation at this point would be to perform this (or a comparable type of) analysis on the ensemble of integrations provided by the various modeling groups to the PCMDI data portal for at least one of the scenarios. Such a study would provide a much greater sample size to analyze further the variance tendencies that have been presented here.

Acknowledgments. The author would like to thank Konstantin Vinnikov for his assistance in applying his analysis scheme to our model results. The author wishes to thank Suki Manabe for his leadership in producing the R30 MCM runs and for his pioneering work, on which many of the results presented here stand. The author also wishes to thank Tom Delworth, Keith Dixon, and Tom Knutson for setting up and integrating the experiments for the R30 model and Michael Spelman for his excellent assistance in extending the experiments run 

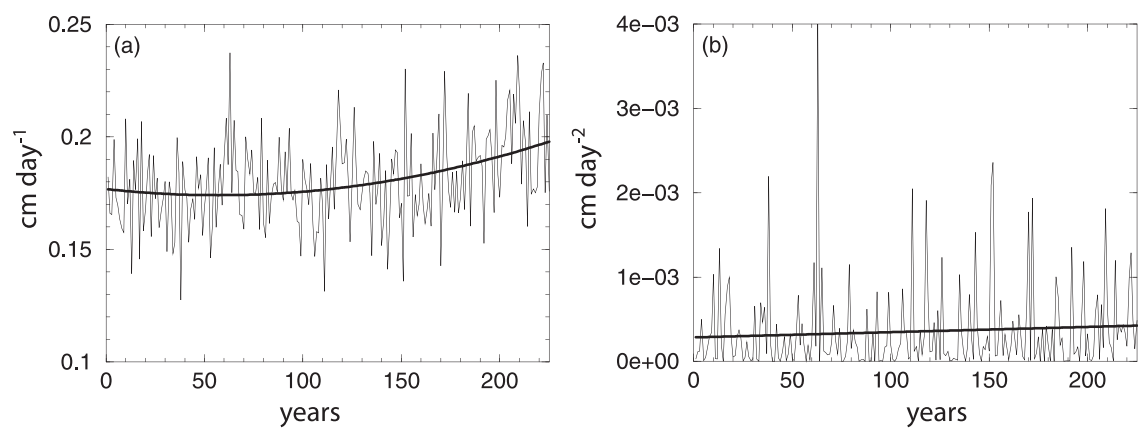

FIG. A1. (a) A typical time series of precipitation at a point in high latitudes (thin line) and the quadratic curve [Eq. (A1)] fitted to that time series (thick line). (b) Time series of variances computed for the same point (thin line) and the corresponding linear fit [Eq. (A3)] to those variances (thick line). Units are (a) $\mathrm{cm} \mathrm{day}^{-1}$ and (b) $\left(\mathrm{cm} \mathrm{day}^{-1}\right)^{2}$.

by Fanrong Zeng for the CM2.1 model. Finally, thanks are due to Kirsten Findell, John Lanzante, and Ronald Stouffer for their constructive reviews and assistance.

\section{APPENDIX}

\section{Computation of Variance}

The method proposed by VR may be outlined as follows: using the VR scheme and terminology, let $y(t)$, $t=t_{1}, t_{2}, t_{3}, \ldots \ldots t_{n}$ be a time series of annual averages of some climate variable $y$ and let $t$ be the year number [in this example, $y(t)$ is the annually averaged precipitation rate]. Assuming that the expected value $E[y(t)]$ may be defined by a quadratic curve, we have

$$
Y_{1}(t)=E[y(t)]=a_{1}+b_{1} t+c_{1} t^{2} .
$$

The coefficients $a_{1}, b_{1}$, and $c_{1}$ may be estimated by a standard least squares technique. Once this is done, the perturbations about this quadratic curve may be computed by using

$y^{\prime}(t)=y(t)-Y(t)=y(t)-a_{1}-b_{1} t-c_{1} t^{2}$.

The variances are obtained as the anomalies about the quadratic curve $y^{\prime}(t)^{2}$ for each point in the time series. The trend in the variance time series is simply a fit with a straight line of the form

$$
Y_{2}(t)=a_{2}+b_{2} t
$$

Again, the coefficients $a_{2}$ and $b_{2}$ are evaluated using a least squares technique. This latter quantity $b_{2}$ or the slope of the line, together with $y^{\prime}(t)^{2}$, will form the basis for the analysis presented in this paper. Therefore, $b_{2}$ represents the trend of the variances.
The VR method has the desirable features that 1) it takes into account that the mean state is changing throughout the transient experiments and 2) it provides a valid time series of variances once the order of the polynomial to remove the mean is determined. A schematic of this method of analysis is shown in Figs. A1a,b. Figure A1a shows the original time series with the quadratic mean curve [Eq. (A2)] fitted to the data from which the anomalies $\left[y^{\prime}(t)\right]$ are computed. Figure A1b shows the resulting time series of variances computed from the information in Fig. A1a along with the linear curve [Eq. (A3)] fitted to the variance time series.

As noted earlier, the only unknown parameter in the VR method is the degree of the polynomial used to remove the trend. K. Y. Vinnikov (2006, personal communication) has indicated that for most variables over the historical record, only a second-order (or quadratic) polynomial is necessary to estimate the changes in the mean state. To test this conclusion, several of the fields shown in this paper were recalculated using a third-order polynomial. It was found that the variance changes were almost identical to the ones obtained from using the second-order polynomial. Based on this analysis, it was decided to use the VR method with a second-order polynomial in the results presented throughout this paper.

\section{REFERENCES}

Alley, R., and Coauthors, 2007: Summary for policy makers. Climate Change 2007: The Physical Science Basis, S. Solomon et al., Eds., Cambridge University Press, 1-18.

Benestad, R. E., 2006: Can we expect more extreme precipitation on the monthly time scale? J. Climate, 19, 630-637.

Brooks, C. E. P., and N. Carruthers, 1953: Handbook of Statistical Methods in Meteorology. Her Majesty's Stationery Office, $412 \mathrm{pp}$.

Delworth, T. L., R. J. Stouffer, K. W. Dixon, M. J. Spelman, T. R. Knutson, A. J. Broccoli, P. J. Kushner, and R. T. Wetherald, 
2002: Review of simulations of climate variability and change with the GFDL R30 coupled climate model. Climate Dyn., 19, $555-574$.

— , and Coauthors, 2006: GFDL's CM2 global coupled climate models. Part I: Formulation and simulation characteristics. J. Climate, 19, 643-674.

Findell, K. L., and T. L. Delworth, 2005: A modeling study of dynamic and thermodynamic mechanisms for summer drying in response to global warming. Geophys. Res. Lett., 32, L16702, doi:10.1029/2005GL023414.

Held, I. M., T. L. Delworth, J. Lu, K. L. Findell, and T. R. Knutson, 2005: Simulation of Sahel drought in the 20th and 21st centuries. Proc. Natl. Acad. Sci. USA, 102, 17 891-17 896.

Houghton, J. T., G. J. Jenkins, and J. J. Ephraums, Eds., 1990: Scientific Assessment of Climate Change. Cambridge University Press, 365 pp.

— B. A. Callander, and S. K. Varney, Eds., 1992: Climate Change 1992: The Supplementary Report to the IPCC Scientific Assessment. Cambridge University Press, $200 \mathrm{pp}$.

_ L. L. G. Meira Filho, B. A. Callander, N. Harris, A. Kattenberg, and K. Maskell, Eds., 1996: Climate Change 1995: The Science of Climate Change. Cambridge University Press, 572 pp.

—, Y. Ding, D. J. Griggs, M. Noguer, P. J. van der Linden, X. Dai, K. Maskell, and C. A. Johnson, Eds., 2001: Climate Change 2001: The Scientific Basis. Cambridge University Press, $881 \mathrm{pp}$.

Hunt, B. G., and T. I. Elliot, 2004: Interaction of climatic variability with climate change. Atmos.-Ocean, 42, 145-172.

Kharin, V. V., F. W. Zwiers, X. Zhang, and G. C. Hegerl, 2007: Changes in temperature and precipitation extremes in the IPCC ensemble of global coupled model simulations. J. Climate, 20, 1419-1444.

Manabe, S., 1969: Climate and ocean circulation. I. The atmospheric circulation and hydrology of the earth's surface. Mon. Wea. Rev., 97, 739-774.

_ ness induced by an increase in atmospheric carbon dioxide J. Atmos. Sci., 44, 1211-1235.

—,- , and R. J. Stouffer, 1981: Summer dryness due to an increase of atmospheric $\mathrm{CO}_{2}$ concentration. Climatic Change, 3, 347-386.

_ P. C. D. Milly, and R. Wetherald, 2004: Simulated long-term changes in river discharge and soil moisture due to global warming. Hydrol. Sci. J., 49, 625-642.

Mearns, L. O., 1993: Implications of global warming for climate variability and the occurrence of extreme climate events. Drought and Assessment Management and Planning: Theory and Case Studies, D. A. Wilhite, Ed., Kluwer, 109-130.

Meehl, G. A., and Coauthors, 2007: Regional climate projections. Climate Change 2007: The Physical Science Basis, S. Solomon et al., Eds., Cambridge University Press, 847-940.
Milly, P. C. D., and A. B. Shmakin, 2002: Global modeling of land water and energy balances. Part I: The Land Dynamics (LaD) model. J. Hydrometeor., 3, 283-299.

— , R. T. Wetherald, K. A. Dunne, and T. L. Delworth, 2002: Increasing risk of great floods in a changing climate. Nature, 415, 514-517.

— K. A. Dunne, and A. V. Vecchia, 2005: Global pattern of trends in streamflow and water availability in a changing climate. Nature, 438, 347-350.

Moorthi, S., and M. J. Suarez, 1992: Relaxed Arakawa-Schubert: A parameterization of moist convection for general circulation models. Mon. Wea. Rev., 120, 978-1002.

Nakicenovic, N., and R. Swart, Eds., 2000: IPCC Special Report on Emissions Scenarios. Cambridge University Press, 570 pp.

Nohara, D., A. Kitoh, M. Hosaka, and T. Oki, 2006: Impact of climate change on river discharge projected by multimodel ensemble. J. Hydrometeor., 7, 1076-1089.

Panofsky, H. A., and G. W. Brier, 1968: Some Applications of Statistics to Meteorology. The Pennsylvania State University, $224 \mathrm{pp}$.

Raisanen, J., 2002: $\mathrm{CO}_{2}$-induced changes in interannual temperature and precipitation variability in 19 CMIP2 experiments. J. Climate, 15, 2395-2411.

Rotstayn, L. D., 1997: A physically based scheme for the treatment of stratiform clouds and precipitation in large-scale models. Part I: Description and evaluation of microphysical processes. Quart. J. Roy. Meteor. Soc., 123, 1227-1282.

Russell, J. L., R. J. Stouffer, and K. W. Dixon, 2006: Intercomparison of the Southern Ocean circulations in IPCC coupled model control simulations. J. Climate, 19, 4560-4575.

Stouffer, R. J., and R. T. Wetherald, 2007: Changes of variability in response to increasing greenhouse gases. Part I: Temperature. J. Climate, 20, 5456-5470.

— A. J. Weaver, and M. Eby, 2004: A method for obtaining initial conditions for use in climate change studies. Climate Dyn., 23, 327-339.

— els. Part IV: Idealized climate response. J. Climate, 19, 723-740.

Sun, Y., S. Solomon, A. Dia, and R. W. Portmann, 2007: How often will it rain? J. Climate, 20, 4801-4818.

Tiedtke, M., 1993: Representation of clouds in large-scale models. Mon. Wea. Rev., 121, 3040-3061.

Vinnikov, K. Y., and A. Robock, 2002: Trends in moments of climatic indices. Geophys. Res. Lett., 29, 1027, doi:10.1029/2001GL014025.

Wang, G., 2005: Agricultural drought in a future climate: Results from 15 models participating in the IPCC 4th Assessment. Climate Dyn., 25, 739-753.

Wetherald, R. T., and S. Manabe, 1995: The mechanisms of summer dryness induced by greenhouse warming. J. Climate, $\mathbf{8}$, 3096-3108.

_ and - 2002: Simulation of hydrologic changes associated with global warming. J. Geophys. Res., 107, 4379-4394. 